\section{Hereditary haemorrhagic telangiectasia: From symptomatic management to pathogenesis based treatment}

European Journal of Human Genetics (2010) 18, 404; doi:10.1038/ejhg.2009.188; published online 4 November 2009
3 Mitchell A, Adams LA, MacQuillan G, Tibballs J, vanden Driesen R, Delriviere L: Bevacizumab reverses need for liver transplantation in hereditary hemorrhagic telangiectasia. Liver Transp/ 2008; 14: 210-213.

4 Bose P, Holter JL, Selby GB: Bevacizumab in hereditary hemorrhagic telangiectasia. N Engl J Med 2009; 360: 2143-2144.

5 Simonds J, Miller F, Mandel J, Davidson TM: The effect of bevacizumab (Avastin) treatment on epistaxis in hereditary hemorrhagic telangiectasia. Laryngoscope 2009; 119: 988-992.

6 Bowcock SJ, Patrick HE: Lenalidomide to control gastrointestinal bleeding in hereditary haemorrhagic telangiectasia: potential implications for angiodysplasias? $\mathrm{Br}$ J Haematol 2009; 146: 220-222.

7 de Gussem EM, Snijder RJ, Disch FJ, Zanen P, Westermann CJ, Mager JJ: The effect of $\mathrm{N}$-acetylcysteine on epistaxis and quality of life in patients with HHT: a pilot study. Rhinology 2009; 47: 85-88.

8 Sadick H, Riedel F, Naim R et al: Patients with hereditary hemorrhagic telangiectasia have increased plasma levels of vascular endothelial growth factor and transforming growth factorbeta 1 as well as high ALK1 tissue expression. Haematologica 2005; 90: 818-828.

9 Ginns LC, Roberts DH, Mark EJ, Brusch JL, Marler JJ: Pulmonary capillary hemangiomatosis with atypical endotheliomatosis: successful antiangiogenic therapy with doxycycline. Chest 2003; 124: 2017-2022.

10 Moses MA, Harper J, Folkman J: Doxycycline treatment for lymphangioleiomyomatosis with urinary monitoring for MMPs. N Engl J Med 2006; 354: 2621-2622.
I read with interest the article 'Hereditary haemorrhagic telangiectasia: a clinical and scientific review' by Govani and Shovlin. ${ }^{1}$ As the authors show in Table 2, treatment of patients with hereditary haemorrhagic telangiectasia (HHT), currently, is primarily symptomatic, without alteration of the underlying pathological process. HHT is a disorder of unbalanced angiogenesis. The vascular endothelial growth factor (VEGF) is upregulated in patients with $\mathrm{HHT}^{2}$ and this factor induces angiogenesis by stimulation of endothelial cell proliferation and migration. Likewise, it stimulates expression of matrix metalloproteinases, which are needed for the degradation of the extracellular matrix in the angiogenic process. In recent years, antiangiogenic drugs have been incorporated into the treatment of HHT. Owing to the important role of VEGF in HHT, drugs against this factor, such as bevacizumab, have been used with favourable outcome in this process. ${ }^{3-5}$ Lenalidomide, a derivative of thalidomide, proved to be useful in a patient with chronic gastrointestinal bleeding as well as sudden massive life-threatening bleeds. ${ }^{6}$ These clinical observations opened the door to the investigation of pathogenesis-based treatment. From a theoretical standpoint, it might be of interest to evaluate other drugs with fewer side effects. ${ }^{7}$ For example, doxycycline is considered to inhibit angiogenesis through the inhibition of matrix metalloproteinases, and matrix metalloproteinases are increased in some patients with $\mathrm{HTT}^{8}{ }^{8}$ This antibiotic appeared to be beneficial in other disorders with unbalanced angiogenesis ${ }^{9}$ or increased activity of matrix metalloproteinases..$^{10}$ Against this background, I believe that it might be of interest to investigate whether doxycycline might have a role in the treatment of some patients with HHT.

\section{CONFLICT OF INTEREST}

The authors declare no conflicts of interest.

Francisco José Fernández-Fernández Department of Internal Medicine, Hospital Arquitecto Marcide, Ferrol, Spain E-mail: fjf-fernandez@terra.es

1 Govani FS, Shovlin CL: Hereditary haemorrhagic telangiectasia: a clinical and scientific review. Eur J Hum Genet 2009; 17: 860-871.

2 Cirulli A, Liso A, D'Ovidio $F$ et al: Vascular endothelial growth factor serum levels are elevated in patients with hereditary hemorrhagic telangiectasia. Acta Haematol 2003; 110: 29-32.

\section{Reply to Fernández-Fernández}

European Journal of Human Genetics (2010) 18, 404-405; doi:10.1038/ejhg.2009.197; published online 4 November 2009

Dr Fernandez-Fernandez ${ }^{1}$ is right in raising the important new data regarding anti-angiogenic strategies in hereditary haemorrhagic telangiectasia (HHT), data which were published too late for inclusion in our review. ${ }^{2}$ Although the gene mutations inform us that HHT is a disorder caused by aberrant signalling by the transforming growth factor (TGF)$\beta$ superfamily, the context in which the gene mutations are deleterious, when functioning apparently perfectly well for the vast majority of vessels, has always proved tantalising. In 2009, there has been a resurgent interest in the role of angiogenesis in provoking or unmasking an HHT phenotype, with animal models particularly implicating a role for aberrant angiogenesis during wound healing. ${ }^{3}$ Pathogenesis-based treatment strategies based on case reports using anti-VEGF (bevacizumab/Avastin), ${ }^{4-6}$ interferon, ${ }^{7,8}$ and thalidomide ${ }^{9,10}$ are being assessed in ongoing clinical trials at HHT centres. For any efficacious agent, sideeffect profiles are likely to be crucial in determining whether the use of any efficacious agents can become more widespread within the HHT patient population. In 2009, encouraging data were also reported for two better-tolerated agents, $N$-acetyl cysteine (trial data for $600 \mathrm{mg}$ $\mathrm{tds})^{11}$ and tamoxifen (randomised placebo-control trial data for $20 \mathrm{mg} /$ day). ${ }^{12}$ These have been introduced into specialised HHT practice, reflecting the rapidly advancing field.

Claire L Shovlin ${ }^{1,2}$ and Fatima S Govani ${ }^{2}$ ${ }^{1}$ HHTIC London, Respiratory Medicine, Hammersmith Hospital, Imperial College Healthcare Trust, London, UK; ${ }^{2} \mathrm{NHLI}$ Cardiovascular Sciences, Imperial College London, Hammersmith Hospital, London, UK E-mail: c.shovlin@imperial.ac.uk 
1 Fernandez-Fernandezovani FJ: Hereditary haemorrhagic telangiectasia: from symptomatic management to pathogenesis based treatment. Eur J Hum Genet 2009, doi:10.1038/ejhg.2009.188 (this issue)

2 Govani FS, Shovlin CL: Hereditary haemorrhagic telangiectasia: a clinical and scientific review. Eur J Hum Genet 2009; 17: 860-871.

3 Park SO, Wankhede M, Lee YJ et al: Real-time imaging of de novo arteriovenous malformation in a mouse model of hereditary hemorrhagic telangiectasia. J Clin Invest 1 October 2009. pii: 39482. doi: 10.1172/JCl39482 [Epub ahead of print].

4 Mitchell A, Adams LA, MacQuillan G, Tibballs J, van den Driesen R, Delriviere L: Bevacizumab reverses need for liver transplantation in hereditary hemorrhagic telangiectasia. Liver Transplant 2008; 14: 210-213.

5 Bose P, Holter JL, Selby GB: Bevacizumab in hereditary hemorrhagic telangiectasia. N Engl J Med 2009; 360: 2143-2144.

6 Simonds J, Miller F, Mandel J, Davidson TM: The effect of bevacizumab (Avastin) treatment on epistaxis in hereditary hemorrhagic telangiectasia. Laryngoscope 2009; 119: 988-992.

7 Massoud O, Youssef W, Mullen K: Resolution of hereditary hemorrhagic telangiectasia and anemia with prolonged [alpha]-interferon therapy for chronic hepatitis C. J Clin Gastroenterol 2004; 38: 377-379.

8 Wheatley-Price P, Shovlin C, Chao D: Interferon for metastatic renal cell cancer causing regression of hereditary hemorrhagic telangiectasia. J Clin Gastroenterol 2005; 39: 344-345.

9 Kurstin R: Using thalidomide in a patient with epithelioid leiomyosarcoma and OslerWeber-Rendu disease. Oncology (Williston Park) 2002; 16: 21-24.

10 Pérez-Encinas M, Rabuñal Martínez MJ, Bello López JL: Is thalidomide effective for the treatment of gastrointestinal bleeding in hereditary hemorrhagic telangiectasia? Haematologica 2002; 87: ELT34.

11 de Gussem EM, Snijder RJ, Disch FJ, Zanen P, Westermann CJ, Mager JJ: The effect of $\mathrm{N}$-acetylcysteine on epistaxis and quality of life in patients with $\mathrm{HHT}$ : a pilot study. Rhinology 2009; 47: 85-88.

12 Yaniv E, Preis M, Hadar T, Shvero J, Haddad M: Antiestrogen therapy for hereditary hemorrhagic telangiectasia: a double-blind placebo-controlled clinical trial. Laryngoscope 2009; 119: 284-288. in HHT patients. As reported by Undas et al., ${ }^{4}$ in the absence of life-threatening haemorrhages and detectable vascular malformations, oral anticoagulation could be considered with strictly haematological and clinical follow-up. An associated thrombotic tendency may confer a survival advantage for HHT patients by decreasing the severity of their bleeding problems. ${ }^{5}$

We suggest that for the clinical management of these patients, genetic tests and counselling for inherited thrombophilia may be useful to prevent vascular and pregnancy complications and that more appropriate pharmacological treatment in consideration of the possible presence of both genetic conditions is used.

\section{CONFLICT OF INTEREST}

The authors declare no conflict of interest.

S Bianca ${ }^{1}, \mathrm{~N} \mathrm{Cutuli}^{2}, \mathrm{M} \mathrm{Bianca}^{3}$, B Barrano ${ }^{1}$, A Cataliotti ${ }^{1}, \mathrm{C}$ Barone $^{1}, \mathrm{~L}$ Indaco ${ }^{1}$ and $\mathrm{G}$ Milana ${ }^{2}$

${ }^{1}$ Centro di Consulenza Genetica e di Teratologia della Riproduzione, Laboratorio di Citogenetica, Dipartimento Materno Infantile, PO Garibaldi-Nesima, Catania, Italy;

${ }^{2}$ Laboratorio di Genetica Molecolare Umana, Az. Osp. Univ. Policlinico, Catania, Italy; ${ }^{3}$ UOC Neurologia - PO Garibaldi-Nesima, Catania, Italy E-mail: sebastiano.bianca@tiscali.it

1 Govani FS, Shovlin CL: Hereditary haemorrhagic telangiectasia: a clinical and scientific review. Eur J Hum Genet 2009; 17: 860-871.

2 Bianca S, Cutuli N, Bianca M et al: Clinical management of Rendu-Osler-Weber syndrome and genetic thrombophilia. Blood Coagul Fibrinol 2009 (in press).

3 Kupferminc MJ, Eldor A, Steinman N et al: Increased frequency of genetic thrombophilias in women with complications of pregnancy. N Engl J Med 1999; 340: 9-13.

4 Undas A, Bazan-Socha S, Swadzba J, Musial J: Hereditary hemorrhagic telangiectasia, factor V leiden and antiphospholipid syndrome: a case report. Blood Coagul Fibrinol 2002; 13: 53-56.

5 Wechalekar A, Parapia L: Hereditary haemorrhagic telangiectasia with protein S deficiency in a family: a case report. Eur J Haematol 2000; 64: 59-60.
European Journal of Human Genetics (2010) 18, 405; doi:10.1038/ejhg.2009.204; published online 11 November 2009
Govani and Shovlin ${ }^{1}$ recently described the clinical and diagnostic implications of hereditary haemorrhagic telangiectasia (HHT). The authors ${ }^{1}$ do not seem to be paying attention to the possible presence of genetic thrombophilic risk in HHT patients in relation to pharmacological treatment. Recently, we published ${ }^{2}$ a case of HHT and genetic thrombophilia with pharmacological complications attributed to the coexistence of both genetic conditions.

In the review paper, the authors ${ }^{1}$ also highlight the risks of life-threatening maternal complications in pregnant HHT women. It is well known that up to $65 \%$ of vascular gestational abnormalities can be accounted for by genetic thrombophilias. ${ }^{3}$ Therefore, it is possible that women with HHT may have recurrent pregnancy loss or other pregnancy complications because of to thrombophilic gene mutations. In the presence of thrombophilic risk, therapy with acetylsalicylic acid and low molecular heparin is recommended, but this may increase the risk of haemorrhages in the presence of HHT. To our knowledge, there are no data on the incidence of pregnancy complications, such as fetal loss or venous thrombosis,

\section{Reply to Bianca et al}

European Journal of Human Genetics (2010) 18, 405-406; doi:10.1038/ejhg.2009.205; published online 11 November 2009

We thank Bianca et al for their interesting comments and hereditary haemorrhagic telangiectasia (HHT) case reports. Within our structured 2009 EJHG review, ${ }^{2}$ we did not have space to discuss in detail all of the implications of the cited studies, including, of relevance here, our large thrombosis ${ }^{3}$ and pregnancy ${ }^{4}$ HHT data series (EJHG references 9 and 48).

Concern regarding thrombophilic risk in HHT patients in relation to pharmacological treatment was one of the main conclusions of our cited (EJHG reference 9) series of 309 HHT-affected individuals. ${ }^{3}$ 